The results thus agree closely with the value 40.142 since obtained by Hinrichsen, who was not cognizant of my work. A further investigation is now being undertaken at Harvard to show whether other methods, executed with great care, support or discountenance this high value.

\title{
COMMERCIAL AQUA AMMONIA, ITS EFFECT UPON IRON, ITS IMPURITIES, AND METHODS FOR DETERMINING THEM.
}

BY J. D. PEN NoCK AND D A. MORTON.

Received Jaxuary 10, 1902.

T $\mathrm{HE}$ very extensive development of refrigerating plants, large and small, throughout the country during the last decade has greatly increased the manufacture of aqua ammonia.

Formerly aqua ammonia of $26^{\circ}$ Bé., or 29. o per cent. $\mathrm{NH}_{3}$, was shipped in carboys. The shipments of aqua soon became so large that it was no longer practicable to transport in such cumbersome and fragile receptacles, and recourse to metal carriers was had. But ammonia was known to attack most metals seriously. W. R. Hodgkinson and N. E. Bellairs' found that all metals which form soluble double salts with ammonium salts are most acted upon by ammonia solution. Zinc, nickel, and cobalt are, after copper, most rapidly attacked. Lead dissolves more slowly, and iron, aluminum, and magnesium do not appear to dissolve at all.

Lunge says" that aqua ammonia in contact with iron, "gives rise to red precipitates of iron oxides."

Lunge's opinion was evidently held by European ammonia manufacturers, for in one of the larger works that the writer visited in Belgium in 1897 , the absorber for the ammonia gas was a lead-lined vessel, and the aqua produced was shipped in carboys.

The opinion was held by certain manufacturers that aqua made from the distillation of sulphate of ammonia with lime would not attack iron, but that aqua made from crude ammonia liquor would.

To ascertain the effect of ammonia on iron and determine if an iron absorber could be used in place of a lead one, and if aqua could be shipped in iron drums and iron cars, various experiments

1 Proc. Chem. Soc., 9, 146 (1895).

2 "Coal-Tar and Ammonia" " p. 685. 
were undertaken. In these experiments, (I) absolutely C. P. aqua, made from C. P. sulphate, distilled with C. P. lime into distilled water, (2) the ordinary commercial aqua, made from sulphate, and (3) several samples, containing different percentages of impurities, all made from the direct distillation of crude liquor without first forming the sulphate, were used.

To ascertain the effect of these different ammonia solutions upon iron, small bottles, 7 inches high and 1.5 inches in diameter, were partly filled with the ammonia solution, and a bright nail, carefully cleaned by filing, was introduced into the solution, and left in contact with it twenty-four hours before examination.

The composition of the ammonia solutions used was:

I. Practically chemically pure aqua, containing 28 per cent. $\mathrm{NH}_{3}$.

2. Aqua from sulphate, containing organic matter equivalent to $10 \mathrm{cc}$. centinormal potassium bichromate per $100 \mathrm{cc}$. aqua, 0.046 gram per liter carbon dioxide, no chlorine, no sulphate, 2 grams per liter pyridine, and 28.5 per cent. $\mathrm{NH}_{i}$.

3. Thirteen samples of aqua from crude liquor containing organic matter equivalent to from 5 to $80 \mathrm{cc}$. potassium dichromate, carbon dioxide from 0.1 to 2 grams per liter, chlorine 0.0 to 0.1 gram per liter, and pyridine, 0.1 to 5 grams per liter, and 28.5 per cent. $\mathrm{NH}_{3}$.

Upon examining the samples after exposing twenty-four hours, it was found that the C. P. aqua, that made from sulphate, and eight of those nade from crude liquor, remained perfectly clear, and the iron was in no way acted upon; but that five were badly attacked, the nail being decidedly rusty, and the solution cloudy with reddish yellow oxide, very finely divided, which remained in suspension and would not settle. It was thought the nails had not been perfectly cleaned, because the composition of the ammonia solutions was so slightly different; five other nails were put into fresh solutions of the same kind, and after twenty-four hours all remained perfectly bright, and the solutions perfectly clear, showing that metallic iron, if perfectly free from specks of rust, is unattacked by strong solutions of ammonia, even if these solutions contain 2 grams per liter carbon dioxide, 5 grams per liter pyridine, and a high percentage of organic matter.

But, of course, it is impossible to so treat the inside of an iron absorber, a drum or tank, that its surface shall be entirely free 
from rust, and consequently when one begins to make aqua ammonia in an iron absorber, or ship it in drums or tank cars, reddish precipitates of iron oxide, which settle with great difficulty, are formed.

Further experiments with iron nails in different stages of oxidation were made with the same solutions, and it was found that a nail freshly rusted forms immediate and continued discoloration of the aqua, while a nail with a thick coating of old rust completely covering the iron does not influence the ammonia solution in the slightest degree.

To be able therefore to absorb strong ammonia solution in an iron vessel, or to ship it in drums or tank cars, it is necessary in some way to coat the surface of the iron with an oxide. This is not an easy matter. Boiling the drum in a weak solution of permanganate of potash will do it, but this is expensive. It has been found, from experiment, however, that by continuous use of the iron absorber, or by repeatedly shipping in drums or cars, this desirable coating is formed, and the aqua is finally not discolored. In the language of the factory, the tank becomes "seasoned," and when this has taken place here is no further trouble from discoloration by iron oxides.

For the rusting of iron it is neceryary that yater, carbon dioxide, and oxygen, must come in contal with he metal.

The reactions illustrating its fornationere:

$$
\begin{aligned}
\mathrm{Fe}+{ }_{2} \mathrm{H}_{2} \mathrm{CO}_{3}=\underset{\substack{\text { Ferrous acid } \\
\text { carbonate. }}}{\mathrm{FeH}_{2}\left(\mathrm{CO}_{3}\right)_{2}}+2 \mathrm{H} . \\
\mathrm{H}_{2}+\mathrm{O}=\mathrm{H}_{2} \mathrm{O} . \\
2 \mathrm{FeH}_{2}\left(\mathrm{CO}_{3}\right)_{2}+\mathrm{O}=\mathrm{Fe}_{2} \mathrm{O}_{3}+4 \mathrm{CO}_{2}+2 \mathrm{H}_{2} \mathrm{O} .
\end{aligned}
$$

Only traces of carbon dioxide and water are necessary to cause continuous rusting.

In the above reaction it is free carbonic acid that reacts with the iron. In ammonia solutions there can be no free carbonic acid, as all carbon dioxide, even in the air above the liquid, is present as ammonium carbonate. It seems quite possible that the weak affinity of iron for carbonic acid would not be sufficient to remove the latter from ammonium carbonate; in other words, it is only free carbonic acid that is available for rusting iron.

All of our experiments with aqua have verified the following conclusions : 
$A$. Concentrated aqua not only does not rust clean iron, but it actually prevents its rusting, even in the presence of water, oxygen, and ammonium carbonate. This conclusion indicates that free carbonic acid is necessary in the rusting of iron.

$B$. If iron, freshly rusted and still moist, be treated with concentrated aqua, the rusting continues for a considerable length of time. In this case we have iron coated, presumably, with more or less ferrous acid carbonate, $\mathrm{FeH}_{2}\left(\mathrm{CO}_{3}\right)_{2}$. This gives off free carbon dioxide and water in contact with the iron, and even in the strong aqua solution the rusting may be indefinitely continued by means of this very small amount of carbon dioxide.

$C$. Iron, which has been rusted for a considerable time, is not affected by concentrated aqua. The iron here is coated with ferric oxide and not ferrous acid carbonate, so there is no carbon dioxide available to cause further rusting.

The impurities to be found to a greater or less degree in aqua ammonia are carbon dioxide, tarry organic matter, pyridine, and seldom, if ever, hydrogen sulphide.

\section{CARBON DIOXIDE.}

The two methods which we have found to be best adapted for the determination of the percentage of carbon dioxide in aqua are what mas the "precipitation" and the "direct titration metwive." The latter is the best, being the most accurate, as well as the most rapid.

Precipitation Method.-To I0o cc. aqua ammonia, in a suitable flask, ${ }^{1}$ add 5 cc. normal sodium hydroxide, ${ }^{2}$ and boil until the bulk of the solution is reduced to about $20 \mathrm{cc}^{3}$ "While still hot add 5 cc. barium chloride solution, drop by drop, and with constant shaking, filter immediately and quickly by suction, and wash the flask and filter five times, using about ro cc. of water for each washing." Return the precipitate and filter to the flask, add excess of fifth-normal sulphuric acid, boil to remore carbon

1 A conical flask of about $300 \mathrm{cc}$. capacity is most convenient.

2 The amount of carbon dioxide in $5 \mathrm{cc}$. of the normal sodium hydroxide must be determined and allowed for in the aqua analysis.

i By boiling down, all ammonia is removed, and all carbon dioxide retained as sodium carbonate.

4 The object of the washing is to remove all traces of sodium hydroxide. The wash-water must be neuttal and free from carbon dioxide, but should contain phenolphthalein, so as to carry out the removal of sodium hydroxide intelligently. The filter will still be slightly pink after washing five times, but this number has been found to give best results. Further washing dissolves barium carbonate and gives too low results. 
dioxide and titrate back with fifth-normal sodium hydroxide, using phenolphthalein as an indicator.

$$
\text { I cc. } \mathrm{N} / 5 \mathrm{NaOH}=0.0044 \text { gram } \mathrm{CO}_{2} \text {. }
$$

No. of cc. N/5 $\mathrm{H}_{2} \mathrm{SO}_{4}-$ cc. N/5 NaOH $\times 0.044=$

$$
\text { grams per liter of } \mathrm{CO}_{2} \text { in the aqua tested. }
$$

The accuracy of this method was tested as follows :

I. IOO cc. of an aqua to which ammonium carbonate had been added was neutralized and the carbon dioxide present very carefully determined by absorption and weighing in the usual way.

Result: $100 \mathrm{cc}$. aqua contained o. 1253 gram carbon dioxide, which, for $25 \mathrm{cc}$. aqua would be 0.03 I 3 gram carbon dioxide.

By the Precipitation Method.-(1) $25 \mathrm{cc}$. aqua contained 0.0315 gram carbon dioxide; (2) $25 \mathrm{cc}$. aqua contained 0.03 I 7 gram carbon dioxide.

II. Tests by this method, omitting the evaporation of solutions containing a known amount of sodium carbonate, resulted as follows :

Carbon dioxide contained,
gram.
0.0042
0.0042
0.0084
0.0084
0.0084
0.0084
0.0168

Carbon dioxide found,
gram.
0.0042
0.0044
0.0079
$0.008 \mathrm{I}$
0.0092
0.0088
0.0169

III. Duplicate determinations, by this method, on 20 samples of aqua, have agreed in every case (with one exception) within 0.00 I gram carbon dioxide per $100 \mathrm{cc}$. aqua.

Direct Titration Method.-I. To Ioo cc. of the aqua, contained preferably in a $300 \mathrm{cc}$. conical flask, add $5 \mathrm{cc}$. normal sodium hydroxide and boil until the bulk of the solution is reduced to about $20 \mathrm{cc}$.

2. To this residue add $50 \mathrm{cc}$. of water (neutral, free from carbon dioxide and containing phenolphthalein), cool to $10^{\circ} \mathrm{C}$, and bring to the neutral point by adding : first, normal sulphuric acid until the end point is nearly reached; next, tenth-normal sulphuric acid until the last trace of pink is just removed. Excess of sulphuric acid must not be present at any time during this neutralization.

3. To the solution thus neutralized add a measured quantity of tenth-normal sulphuric acid (usually ro cc.), boil two 
minutes to remove carbon dioxide, cool, and titrate back with tenth-normal sodium hydroxide.

(No. of cc. $\left.\mathrm{N} / 10 \mathrm{H}_{2} \mathrm{SO}_{4}-\mathrm{cc} . \mathrm{N} / 10 \mathrm{NaOH}\right) \times 0.044=$

grams per liter $\mathrm{CO}_{2}$ in the aqua.

The carbon dioxide contained in $5 \mathrm{cc}$. normal sodium hydroxide must be determined and allowed for in the aqua analysis.

Concerning the respective steps of this analysis the following facts may be noted:

$r$. When aqua ammonia is boiled down in the presence of sodium hydroxide all carbon dioxide is retained as sodium carbonate, even though the evaporation be carried nearly to dryness. The purpose of boiling down with sodium hydroxide is to remove all ammonia, to reduce the bulk of the solution, and to retain all carbon dioxide as sodium carbonate.

2. The addition of acid as described, will set free a little carbon dioxide which may partially volatilize from the solution if the latter be too concentrated. By dilution with $50 \mathrm{cc}$. of water, this cause of error is averted.

Before bringing to the neutral point the solution must be cooled to a low temperature (below $10^{\circ} \mathrm{C}$.), otherwise the phenolphthalein color end point is not sufficiently distinct. Also there is less liability of loss of carbon dioxide by too rapid addition of acid, if the solution be well cooled.

The end-point is just reached when sufficient acid has been added to convert all the sodium carbonate into sodium bicarbonate, since the former is alkaline and the latter neutral to phenolphthalein. This neutralization is represented by the equation:

$$
2 \mathrm{Na}_{2} \mathrm{CO}_{3}+\mathrm{H}_{2} \mathrm{SO}_{4}=\mathrm{Na}_{2} \mathrm{SO}_{4}+\mathrm{NaHCO}_{3} .
$$

Excess of sulphuric acid must not be present at any time during this neutralization, because it will almost certainly cause a loss of carbon dioxide before excess of alkali can again be added.

3. The final step is the decomposition of the sodium bicarbonate by addition of an excess of sulphuric acid, the removal of carbon dioxide by boiling, and the titration of the excess of sulphuric acid by alkali.

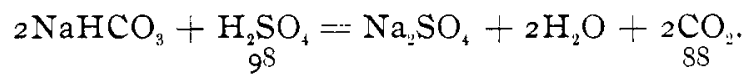


One cc. tenth-normal sulphuric acid (0.0049 gram stulphuric acid) sets free 0.0044 gram carbon dioxide.

Hence :

(No. of cc. $\mathrm{N} / \mathrm{IO}_{2} \mathrm{SO}_{4}-$ cc. $\mathrm{N} /$ Io $\mathrm{NaOH}$ ) $\times 0.0044=$

grams $\mathrm{CO}_{2}$ in $100 \mathrm{cc}$. aqua.

RESULTS.

Tests with Sodium Carbonate Solutions Containing a Known Amount of Carbon Droxide.

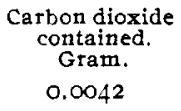

0.0084

0.0168

0.0084

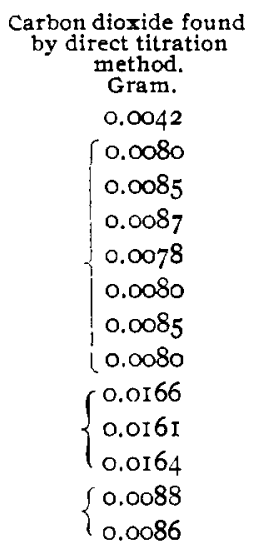

The last two determinations were made at night, by the light of incandescent lamps.

A large number of determinations of carbon dioxide in aqua by this method, and a comparison of its results, on the same aquas, with those obtained by the precipitation method, have fully confirmed its accuracy.

\section{CONCLUSIONS.}

From the results obtained the conclusion is reached that the direct titration method for carbon dioxide in aqua ammonia is, all points considered, the best. It is accurate, rapid, and simple.

Equally accurate results can scarcely be obtained by the precipitation method, and the direct titration method requires less careful manipulation, takes less time, and avoids the liability to error which is occasioned by precipitation and washing of the barium carbonate. On the other hand in using the direct titration method, sulphides, if present, must be removed before making the titrations, while this removal is unnecessary in the case of the precipitation method. 
Tarry organic matter, as found in ammonia, is best determined by oxidation with potassium bichromate instead of potassium permanganate, which in the cold does not completely oxidize, and at boiling temperature is itself decomposed, whereas potassium bichromate does not undergo decomposition, and with its use check results may be obtained even at different times of boiling. The method was devised by Mr. J. G. Hazard, and is the one ne have adopted.

Potassium permanganate affects pyridine slightly, but by no means entirely oxidizes it. We therefore prefer to make a test for the organic matter with potassium bichromate which does not oxidize pyridine at all, and then make a separate determination of the pyridine. The method is as follows:

DETERMINATION OF ORGANIC MATTFR IN AQUA AMMONIA.

Make up fiftieth-normal solutions of ammonium sulphate, ferrous sulphate, potassium permanganate, and potassium bichromate.

Introduce Iocc. of aqua (from pipette) into a $300 \mathrm{cc}$. Erlenmeyer flask, add $20 \mathrm{cc}$. fiftieth-normal potassium bichromate solution (from burette), and $50 \mathrm{cc}$. dilute sulphuric acid ( $\mathrm{I}: 3$ ). Heat to boiling and boil gently for about twenty ninutes, adding distilled water if necessary to keep the volume above $50 \mathrm{cc}$. After boiling, cool to temperature of the room and add fiftieth-normal ammonium ferrous sulphate solution (from burette) in excess, and titrate back to faint pink color with fiftieth-normal potassitum permanganate. The pink color will always fade out in a short time.

Add number of cubic centimeters potassium permanganate used, to number of cubic centimeters potassium bichromate used, and subtract number of cubic centimeters ammonium ferrous sulphate used. Deduct number of cubic centimeters potassium bichromate used up in a blank sample, and report result as number of cubic centimeters centinormal potassium bichromate used per roo cc. aqua.

The end-point of the method appears to be perfectly definite, no further oxidation occurring by boiling considerably longer than the prescribed twenty minutes. The results obtained have indicated that all organic coloring-matter, or compounds which may change over into colored products are determined by this 
method, while pyridine, and perhaps other stable organic bodies, are unattacked. A sample of aqua to which pure pyridine had been added gave almost exactly the same result as it gave by a test before the addition.

\section{PYRIDINE.}

Pyridine in aqua to be used in making liquid ammonia causes much trouble in the compressors and must be kept down to a low figure.

For the detection of traces of pyridine in commercial ammonia, "H. Ost recommends that the sample should be nearly neutralized when the odor of pyridine may be recognized. By distilling the nearly neutralized liquid, collecting the distillate in hydrochloric acid, evaporating, and extracting the residue with absolute alcohol, a solution is obtained containing but little ammonium chloride. What is present is removed by boiling off the alcohol and adding platinic chloride solution when, on evaporating the filtrate and adding alcohol, the pyridine chloroplatinate crystallizes in smooth, ramifying, orange-red prisms, readily soltuble in boiling, but very sparingly in cold water."

But this is only a qualitative determination, while the following method gives excellent results quantitatively :

DETERMINATION OF PYRIDINE IN AQUA AMMONIA.

Ioo cc. of the aqua are nearly neutralized with sulphuric acid ( $1: 5$ ), keeping the mixture moderately cool meanwhile, so that pyridine will not be volatilized. Finally, cool to $20^{\circ} \mathrm{C}$, add I or 2 drops of methyl orange and bring exactly to the neutral point with normal acid and alkali.

This neutral mixture is then placed in a suitable distilling flask and distilled until $70 \mathrm{cc}$. have passed over, the distillate being collected in $30 \mathrm{cc}$. of cold water contained in a small receiver.

Unless the aqua contains an unusually large amount of pyridine (i.e., over 2.5 grams per liter), the roo cc. of liquid now in the receiver contain all the pyridine which was present in the aqua and a small amount of free ammonia. The amount of ammonia $\left(\mathrm{NH}_{3}\right)$ which is thus carried over will usually be equivalent to about $2 \mathrm{cc}$. normal solution.

Cool the contents of the receiver to below $10^{\circ} \mathrm{C}$, , add phenolphthalein, then, from a burette, mercuric chloride solution until 
the last trace of pink is just removed, and finally 4 drops more of mercuric chloride solution to insure complete removal of the anmonia.

The mercuric chloride removes all the free ammonia according to the equation

$$
\mathrm{HgCl}_{2}+2 \mathrm{NH}_{3}=\underset{\text { white precipitate }}{\mathrm{NH}_{2} \mathrm{HgCl}}+\mathrm{NH}_{1} \mathrm{Cl} \text {. }
$$

Phenolphthalein is colored by free ammonia, but not by pyridine, so that the pink color of the solution is just removed when all the free ammonia has been acted upon.

The mixture is now filtered and the filtrate, containing pyridine bases alone, is titrated with normal sulphuric acid, after adding one drop of methyl orange for an indicator.

I cc. normal $\mathrm{H}_{2} \mathrm{SO}_{4}=0.079$ gram pyridine.

RFSULTS OF DETERMINATIONS OF KNOWN QUANTITIES OF PYRIDINE IN Agu.A.

$\begin{array}{cllllll}\text { Grams per liter present... } & \text { I.I6 } & 2.16 & 4.16 & 2.2 & \text { I.I6 } \\ . " & . " \text { " found ... } & \text { I.II } & 2.0 & 4.1 \text { I } & 2.3 & \text { 1.I5 }\end{array}$

Water, to which a knowu quantity of pyridine was added, was carried through the method.

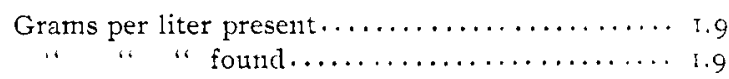

In the manufacture of aqua it is a great convenience to know, without making an analysis, the percentage of ammonia in an aqua by simply taking the degree Baumé. The temperature of the manufactured article as it leaves the absorber, of course, varies slightly.

Having determined the percentage of ammonia in three samples of different strengths, we have found the degree Baumé of each at temperatures varying from $10^{\circ} \mathrm{C}$. to $30^{\circ} \mathrm{C}$., and after plotting these on a chart, we have worked up the following table, by which, at a glance, one may learn the percentage of ammonia in a given sample of aqua, having determined the temperature and degree Baumé.

In shipping strong aqua, 29 to 30 per cent., to a hot climate in tank cars, one must take into consideration the great expansion of ammonia at temperatures which are likely to prevail in the summer months, and see to it that his tank will withstand the pressure as, of course, the tank will be sealed up. The following 
Oे 0 o

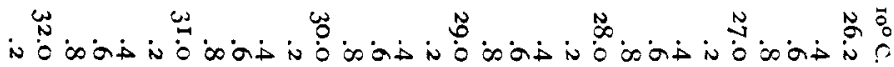

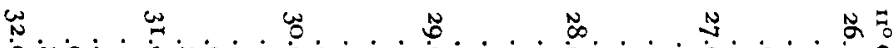

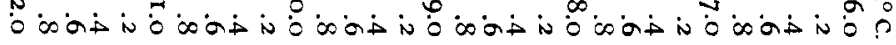

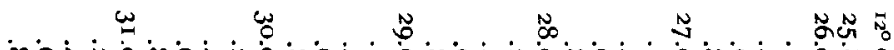

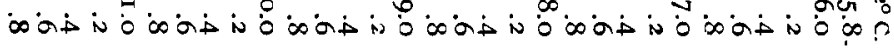

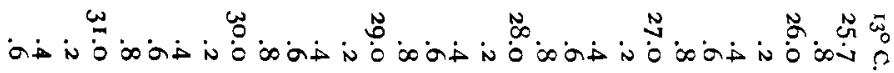

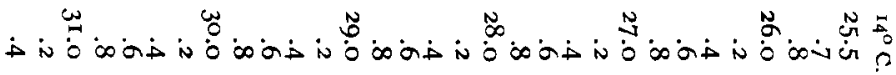
i

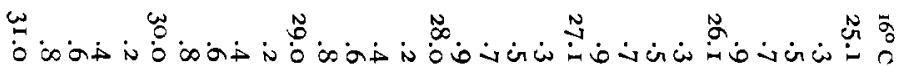

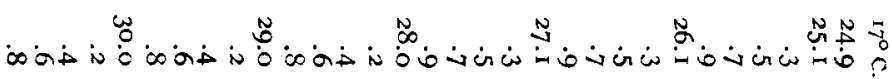
W N

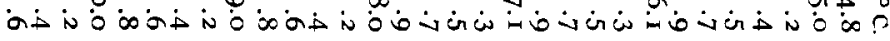

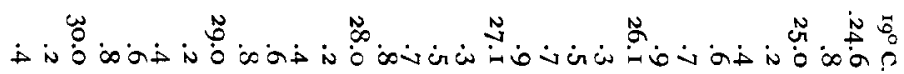
i

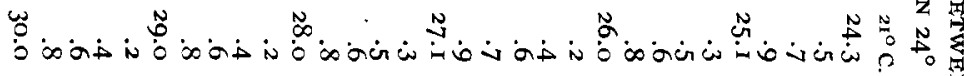

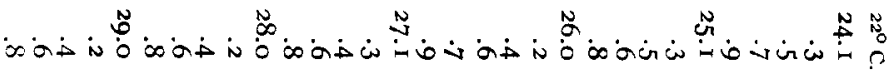

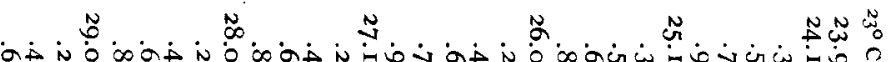

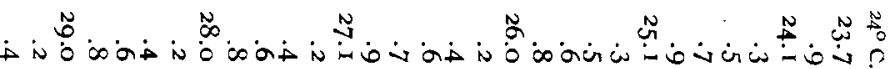
i

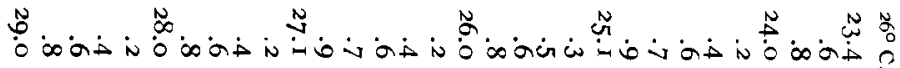

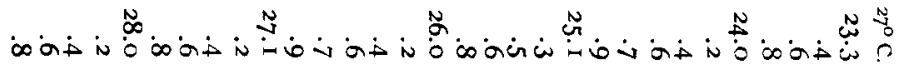

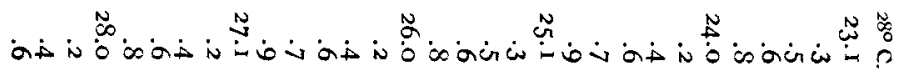
$\underset{3}{3}$ 70 9 3
3
3
2
$z$
$z$
$z$ 
table shows the pressure developed by strong ammonia solutions exposed to different temperatures :

PRESSURE PRODUCED BY EXPOSING AQUA AMMONIA TO DIFFERENT TEMPERATURES.

The apparatus in which this test was made consisted of a cast-iron fitting piece with a pressure gauge and a mercury gauge attached. The relation of the liquor to the unoccupied space of the apparatus was the same as the relation of liquor in a tank car to the unoccupied space of the car. The apparatus was set in a water tank which was heated externally, and readings of the pressure gauge end of the mercury gauge made at every degree of temperature. The thermometer was placed in the aqua.

Experiment was carried to $120.2^{\circ} \mathrm{F}$.

The rate of heating was $I^{\circ}$ every six minutes.

The percentage of ammonia was 28.5 , and the number of cubic centimeters aqua used was 2800 .

\begin{tabular}{|c|c|c|c|c|c|c|c|}
\hline${ }^{\circ} \mathrm{c}$. & ${ }^{\circ} \mathrm{H}$, & $\begin{array}{l}\text { Pounds } \\
\text { pressure. }\end{array}$ & $\begin{array}{l}\text { Inches } \\
\text { mercuty }\end{array}$ & ${ }^{\circ} \mathrm{C}$ & ${ }^{\circ} \mathrm{F}$, & $\begin{array}{l}\text { Pounds } \\
\text { pressure. }\end{array}$ & $\begin{array}{l}\text { Inches } \\
\text { mercury }\end{array}$ \\
\hline 23 & $73 \cdot 4$ & $21 / 2$ & $4 \%$ & 37 & 98.6 & IO $1 / 2$ & $213 / 4$ \\
\hline 24 & 75.2 & 3 & 65 & 38 & 100.4 & I I & 22 \\
\hline 25 & 77.0 & 4 & $71 / 2$ & 39 & 102.2 & I I $1 / 2$ & 233 \\
\hline 26 & 78.2 & $41 / 2$ & $8 t_{4}$ & 10 & IO4 & I 2 & $24 \frac{3 / 4}{4}$ \\
\hline 27 & 80.6 & 5 & $9: 4$ & $4 I$ & 105.8 & $121 / 2$ & $251 / 2$ \\
\hline 28 & 82.4 & 5 & $10 I_{4}$ & 42 & 107.6 & $I_{3}$ & 2634 \\
\hline 29 & 8.2 & 5 & I I $I_{4}$ & 43 & 109.4 & $131 / 2$ & 274 \\
\hline 30 & 86 & 6 & $12 \frac{1}{2}$ & 44 & III. 2 & I4 & 283 \\
\hline $3 \mathrm{I}$ & 87.8 & $61 / 2$ & $13^{3} 4$ & 45 & I 33 & $14 / 2$ & 293 \\
\hline 32 & 89.6 & 8 & 16 & 46 & 114.8 & I 5 & 3034 \\
\hline 33 & 91.4 & 8 & $171 / 2$ & 47 & I I 6.6 & $151 / 2$ & 31 \\
\hline 34 & 93.2 & 9 & 1814 & 48 & 118.4 & I 6 & 3234 \\
\hline 35 & 95 & $9^{1 / 2}$ & 19 & 49 & 120.2 & $161 / 2$ & $33^{3}+$ \\
\hline 36 & 96.8 & IO & $201 / 2$ & & & & \\
\hline
\end{tabular}

\section{A NITROGEN APPARATUS.}

BY J. A. WESENER

Received November 20,190 :

$T$

$\mathrm{HE}$ purpose of this apparatus, as illustrated and described herewith in detail, is to secure greater rapidity in the ordinary nitrogen estimation. The method adopted in this apparatus for estimating nitrogen is by distilling the alkaline mixture in a current of steam, using the same steam which makes the 